\title{
On Idealizations and Models in Science Education
}

\author{
Jan Winkelmann ${ }^{1}$ (D)
}

Accepted: 29 September 2021 / Published online: 19 October 2021

(c) The Author(s) 2021, corrected publication 2022

\begin{abstract}
Idealizations are omnipresent in science. However, to date, science education research has paid surprisingly little attention to the use of idealizations in fostering students' model competence and understanding of the nature of science (NOS). The starting point for the theoretical reflection in this paper is that insufficient consideration of idealizations in the science classroom can lead to learning difficulties. The following discussions should help to clarify the terms idealization and model and their relationship to each other. An example is drawn from physics. At least two cases can apply when considering model usage in the classroom. In the first case, to understand an observed phenomenon, a model (as a representation) of the situation to be explained is constructed. At this point, it is necessary to perform idealization. Seemingly, this step is still neglected in much of the science education literature but is well addressed in the philosophy of science. In the second case, existing models to work with are introduced, perhaps alongside a real experimental situation. This approach is called working with models in science education. This paper focuses primarily on the first case. Against the background of model building, a positioning and conceptual approximation of idealizations take place. To organize the idealization process, a framework of several categories of idealization adopted from science philosophy is offered. The framework is intended to stimulate explicit reflection about how models are constructed. The construction of a model by idealization is illustrated through an example from geometrical optics. Finally, the considerations presented are discussed in the context of the literature, and suggested research topics are provided.
\end{abstract}

\section{Introduction}

The goal of science education research is to provide better insights into the challenges of learning science. Focusing on the improvement of students' understanding of science in the broadest sense, students should not only learn facts but also learn how science works, such as competencies in scientific literacy (National Research Council (NRC), 2007). Following this approach to maintaining students' understanding, in Hodson's (2014) sense, the teacher changes the learning goal from learning science to learning about science. This is

Jan Winkelmann

jan.winkelmann@ph-gmuend.de

1 Institute of Natural Science, Physics Department, University of Education Schwäbisch Gmünd, Oberbettringer Straße 200, 73525 Schwäbisch Gmünd, Germany 
a transition from cognition to metacognition. Learning about science involves aspects of the nature of science (NOS). Hodson is not alone in this approach, as a substantial body of research exists that is concerned intensively with explicit approaches to the NOS (e.g., Akerson et al., 2007; Khishfe \& Abd-El-Khalick, 2002; Lederman et al., 2014; Schwartz et al., 2004). A crucial issue in the NOS is working with models and examining their plausibility (Lederman, 2007; Lederman et al., 2002; Lehrer \& Schauble, 2006; Schwarz et al., 2009; Sins et al., 2009). Thus, modeling is a central part of scientific literacy (Gilbert \& Justi, 2016). In the end, learning requires transparent and well-argued reflection in learning processes that lead students to profound understandings.

Models always apply only within defined limits that are determined by the purpose of the model and the idealizations on which the model is based. Within these limits, they provide credible insights. At the same time, (scientific) knowledge, including models, is provisional and subject to a certain degree of uncertainty (Allchin, 2013; Höttecke \& Allchin, 2020; Lederman et al., 2002). Therefore, science teachers are in a state of tension in their lessons. On the one hand, explanations are to be offered to the classes in as clear and structured a manner as possible, which includes a certain amount of trust in the content conveyed. On the other hand, the preliminary nature of models should be considered in the course of NOS education (Germany: KMK, 2005, or USA: NGSS Lead States, 2013).

Working with models provides an essential contribution toward insights about and the acceptance of reliable knowledge in science (classroom). The considerations in this paper start one step earlier and ask how models (as representations) are actually created. They are the results of cognitive effort and are constructed by humans. Idealizations are necessary for the process of model construction. Idealizations are omnipresent in the sciences. For example, thermodynamic laws are based on an ideal gas; idealized properties are attributed to atomic models that they do not have at all; and masses can sometimes be assumed to be punctiform. The meaning of idealizations also applies to the process of experimentation, which, however, will not be examined in more detail in this paper. In the context of experimental manipulation, the interplay between idealizations and empirical evidence in psychological and epistemological theories has been discussed, e.g., in Matthews (1987) or Niaz (1999).

The importance of idealizations is a topical issue in the philosophy of science (e.g., Potochnik, 2017). This paper will show that idealizations are ubiquitous even in science classes, e.g., when modeling natural phenomena. While the modeling process can be a door opener for scientific literacy, the method also constitutes a significant hurdle for learners to quickly understand and follow scientific explanations (Winkelmann et al., 2021; Leisner, 2005; Romer, 1993).

This paper will propose theoretical aspects of the interplay between idealization and modeling. It addresses teachers at universities and schools. A theoretical, reflective examination of idealizations is offered instead of a practical teaching approach (e.g., in Kipnis, 1998). Against a theoretical background of model competence that needs to be further promoted (Section 2), this paper outlines the debate on idealizations as a way to initiate an explicit promotion of NOS. For this purpose, a conceptual approximation of idealizations takes place and a framework for identifying and reflecting idealizations are presented. Both are then deepened using an example from optics (Section 3). Finally, advantages of the framework are presented and suggestions for further research areas are provided (Section 4). 


\section{Theoretical Background}

In the following, current research on modeling is briefly summarized so that the characteristics and functions of idealizations can be oriented in the field. In this way, a research desideratum and starting points for dealing with idealizations are presented.

\subsection{Idealization as Part of Model Building}

When teaching about science, especially with regard to models, a physics teacher should have a widely agreed-upon set of competences at one's disposal, as summarized by Tempel et al. (2018): to model phenomena, to develop models, to use models adequately, to cause conceptual change, to recognize preconceptions, to distinguish models, to have knowledge about models in the history of physics and to have philosophical knowledge about models. A review shows that not every competence (of teachers or students) is treated the same way in the literature. A considerable amount of literature about models and modeling exists in science education research (e.g., Gilbert \& Boutler, 1998; Gobert et al., 2011; Pluta et al., 2011; Rönnebeck et al., 2016; Schwarz \& White, 2005; Treagust et al., 2002). Within these works, there is a strong focus on how models can be used to obtain a better understanding of (phenomena in) science. Based on the literature of science philosophers and science education researchers, Oh and Oh (2011) provide a broad overview of the nature of models and their use in science classrooms. They summarize five purposes of modeling, which their reported studies have in common: (1) the meanings of a model, (2) the purposes of modeling, (3) the multiplicity of scientific models, (4) changes in scientific models, and (5) the uses of models in the science classroom. Here, too, the focus lies on working with models rather than on their construction. Coll et al. (2005) report that conveying the meaning of models takes place most effectively "when students are able to construct and critique both their own, and scientists' models of scientific phenomena" (p. 194). In doing so, Coll et al. (2005) emphasize the benefits and limits of models as representation.

Louca and Zacharia (2012) see model-based learning as being closely related to students' learning in general. Model-based learning covers cognitive, metacognitive, social, material, and epistemological contributions. As a conclusion of their review on modelbased learning, the authors recommend that model-based learning be incorporated into school science curricula in an epistemologically meaningful way. According to a literature review on modeling-based teaching (Gilbert \& Justi, 2016), there is little research concerning the construction of models through idealization. The metacognitive and explicit processes of constructing and reflecting on a model—namely, through idealizations—seems to be of less interest. Few studies have been dedicated to individual aspects of the model construction, e.g., simplifying assumptions (Etkina et al., 2006), investigating the question of an approximation to reality (Portides, 2007), or examining the significance of the abstractness of models to the model competence of students (Shemwell \& Capps, 2019). Nevertheless, the philosophy of science has addressed this issue intensively (see Section 2.2).

The following is intended to clarify what is understood by a model in this paper and to what extent idealizations are part of model building in the modeling process.

Schwarz and White (2005) define models "as a set of representations, rules, and reasoning structures that allow one to generate predictions and explanations" (p. 166). Their definition appropriately describes the product and the aim of the modeling. Gouvea and Passmore (2017) emphasize the function of models as tools and differentiate between models of 
(medium) and models for (tool) something. However, in both cases, it should be understood on what basis the models were created: idealization. Gut et al. (2016) describe two phases of modeling: first, the construction of a model through simplification and idealization, and second, the testing of the model. The authors suggest working with idealization for construction. Unfortunately, however, they do not express exactly what they mean. Their focus is more on methodological implementation than on an epistemological approach. Gilbert and Justi (2016) provide a sophisticated model of modeling based on Hestenes (1987) and Clement (1989). They describe two views of models: the models as representations view and the models as epistemic artifacts view; the latter focuses more on the construction of models (Gilbert \& Justi, 2016, p. 17). They also define an in-depth, step-by-step procedure for describing the process of modeling. A similar approach is presented by Krell et al. (2016). To bring modeling and experimentation into a structural model of scientific thinking, Teichrew and Erb (2020) developed a circle of learning about science involving four stations, which can be seen as learning objects or starting points for further research. The four stations comprise (1) the identification of phenomena, (2) the construction of an explanatory model, (3) the formulation of hypotheses to be tested in (4) an experiment. Stations one and two are the most relevant to this paper. On a meta-level, current studies have attempted to identify a model of students' modeling competence. Upmeier zu Belzen et al. (2019) suggest a framework with three levels of competence, varying in five aspects (the nature of models, multiple models, the purpose of models, testing models, and changing models). For this paper, the nature of models aspect is the most important. The authors distinguish between models are copies of something (level 1), models are idealized representations of something (level 2), and models are theoretical reconstructions of something (level 3).

\subsection{Idealizations as Epistemic Artifacts}

When thinking about models in science, there are multiple meanings associated with the term model. These meanings are connected with each other; building on the idea that idealizational constructs are the central concept of the models that lie at the heart of science (Nowak \& Nowak, 1998), other kinds of models, such as analogical models and models as devices to simulate a phenomenon, are derivative notions. Analogies serve a role in the formation of idealized constructs by referring to the known (Kipnis, 1998), and simulation models help to test such constructs for empirical adequacy. Idealization occurs functionally and conceptually before analogies and simulations. This paper argues that a closer look at the construction of models is warranted and intends to raise awareness of modeling in science education at school. This perspective is built upon a general consideration of what a model as a representation (Gilbert \& Justi, 2016, p. 17) represents: "a set of properties and causal relations" (Strevens, 2017, p. 6).

The distinction between models as epistemic artifacts and models as representations by Gilbert and Justi (2016) appears to be helpful and creates clarity surrounding the use of modeling. However, the term epistemic artifact needs to be explained here. Epistemology deals with the theoretical conditions for well-founded knowledge. Epistemology, i.e., a theory of knowledge, has to be about more than just the question of what makes knowledge scientific. This paper joins Rheinberger's (2007) opinion, which notes that epistemology is about "reflecting on [...] the means by which things are made objects of knowledge, which the process of gaining scientific knowledge is set in motion and kept it going" (translated by the author). It is precisely these means that represent idealizations in the context 
of models. In the fundamental reciprocal relation between (experimental) phenomena and theoretical knowledge, Halloun (2004) understands idealized assumptions in models as mediators between such phenomena and theory. These assumptions are understood in a similar way in this paper. In contrast to Morrison and Morgan (1999), however, a broader understanding of the term mediator does not imply that models are regarded as independent of theory and the world. Rather, the view of Knuuttila and Voutilainen (2003) is that models are always part of a "purposeful human activity" (p. 1484). Of course, models can serve as mediators only for someone who has relevant background knowledge and is very aware of the nature of a model, which highlights the importance of idealizations. Different categories of idealizations - understood as epistemic artifacts-are presented in Table 1 and examples are given in Section 3.3.

All models, whether they are epistemic artifacts or representations, have in common that they are idealized constructs. With knowledge of the underlying idealizations such epistemic artifacts can be used to construct models as representations. Several representations of models can serve to test a constructed model. Figure 1 attempts to summarize a description of models and idealizations and their locations within the mutual examination of experiment and theory.

According to Hodson (1993), not only learning science but also learning about science is a fundamental learning goal of science teaching and must be explicitly addressed in the classroom. He understands this as the interplay between experiment and theory. Taking this into account, and following epistemological considerations as mentioned above, this proposes placing the modeling process between the observation of (experimental) phenomena and theoretical knowledge. The focus is on constructing models with idealizations as a precondition for modeling (Fig. 1). Taking into account research on models of modeling (e.g., Gilbert \& Justi, 2016, p. 32), the process of idealization occurs at the beginning of the modeling process. Idealization takes place after reflecting on the purpose of the model and before the representation exists. One essential further step is to work with the constructed models; this step has often been mentioned in other papers already and is therefore not the subject of this paper.

The idea of idealizations in physical explanations has a fairly long tradition, and its origin is often attributed to Galileo Galilei (1564-1641). He established the starting point for thinking in models. It is a well-known historical fact that Galileo's postulation of the idea of inertia started from his observation of pendulum motion and proceeded in constructing idealized models and developing a more comprehensive scientific principle (Haase, 1996; Losee, 2001; Matthews, 2004; Nola, 2004). Other physicists, such as Heinrich Hertz (1857-1894), also thought about modeling and emphasized the importance of idealizations in constructing representations of observed nature:

[...] the images, we talk about, are our perception of the things; they conform to the things in one essential way, which is in the fulfillment of the mentioned demand, however, for their purpose no further fulfillment with the things is necessary (Hertz, 1894, p. 1).

This means that in the course of modeling, simplifications and thus falsifications are accepted. Which in turn leads one to wonder why anything at all can be understood through modeling. In the philosophy of science, a connection between idealizations and the comprehension of science phenomena is postulated (Potochnik, 2017; Strevens, 2017), and it is discussed to what extent fiction (idealized scientific representations) can promote understanding (e.g., Elgin, 2008). Especially on a causative level as opposed to an explanatory level, idealization may be fundamental. Strevens (2017) intensifies those considerations by 


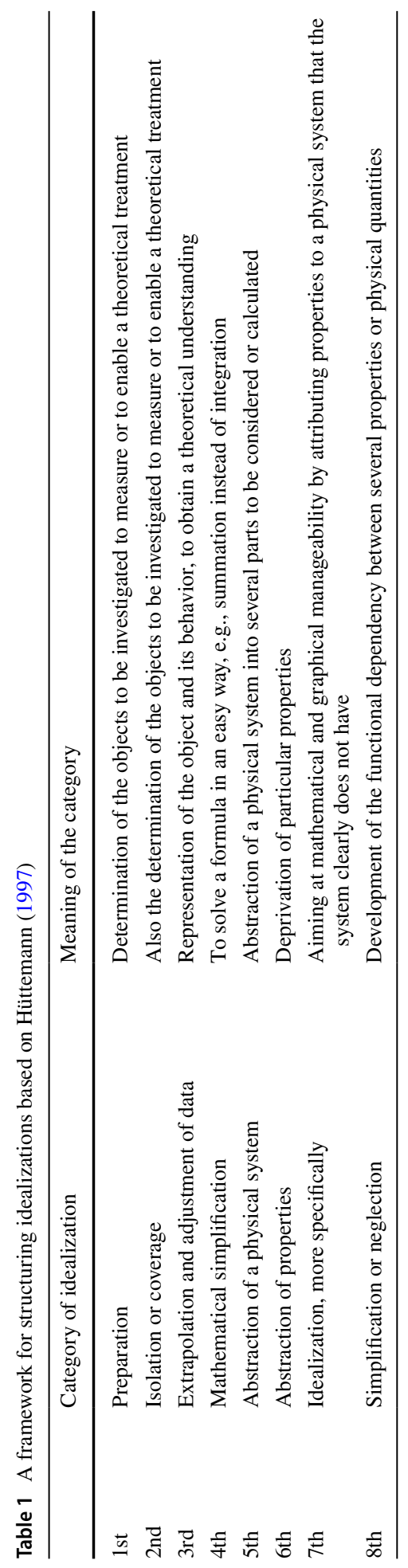




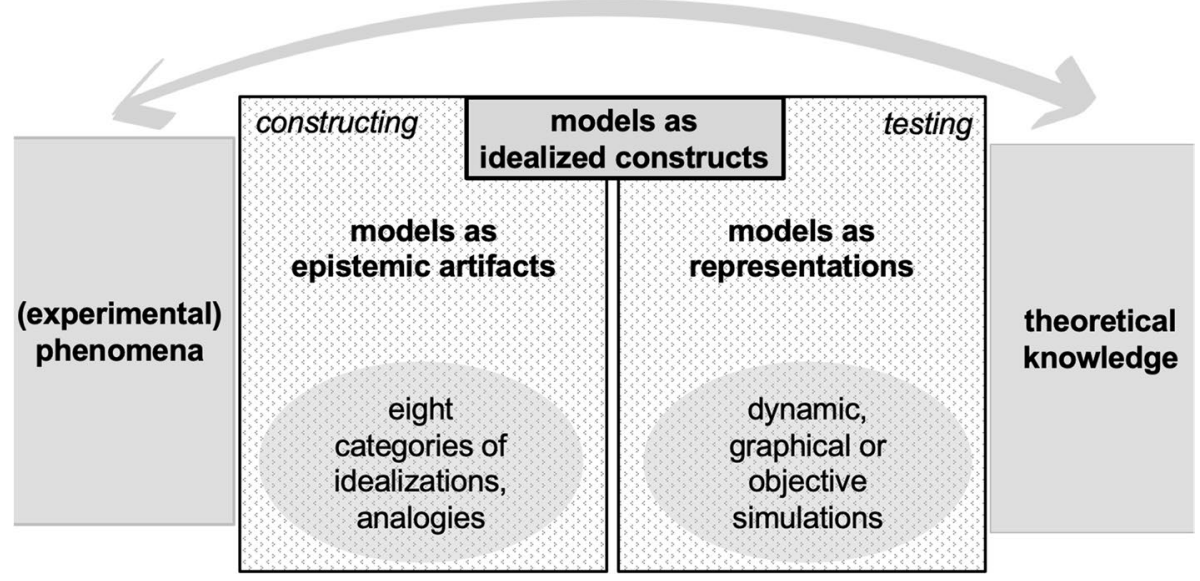

Fig. 1 Models as idealized constructions are placed in the middle, between (experimental) phenomena, and theoretical knowledge

asking whether a falsehood will contribute to a better understanding and affirms that it will, since many explanatory models use idealizations that are intended to be seen as deliberate falsifications.

\subsubsection{Conceptual Approximation to Idealization}

Idealizations are more than just simplifications that may appear first in introductory texts and disappear later, to be replaced by more complex descriptions from advanced science. To work with idealizations, whether in science lessons at school or in the context of teacher training, this paper understands the following as idealizations.

1. The purpose of idealizations is to approach a complex reality. For this, the individual properties of an object under consideration are deliberately replaced. The focus is on only those properties that are felt to be essential to the goal of an investigation (Nowak \& Nowak, 1998).

2. The goal of idealization is to be able to answer a question about nature. Idealizations are based on the requirement of optimizing an explanation: In the search for knowledge, idealizations are deliberate substitutions for actual processes. False assumptions are consciously accepted (Hüttemann, 1997; Potochnik, 2017).

Idealizations, therefore, have two interrelated characteristics. On the one hand, idealizations are limited to the essentials and depend on the question of what the essentials are. On the other hand, idealizations always represent a consciously reductive replacement. However, despite this reduction, an evaluation of the constructed models remains justified, if not even necessary. Such an assessment should be made with regard to the usefulness of the model rather than on whether the model is right or wrong. It is supposed fundamentally that theoretical descriptions are always idealizations from several perspectives and do not correspond with the real world (Chalmers, 1999; Kipnis, 1998).

In contrast to idealizations, didactic reductions prepare learning content appropriately for the target group, e.g., photosynthesis for a seventh grade class. The corresponding 
educational decisions are usually hidden from the learners. On the other hand, idealizations are already included in the learning objects and can even become a learning object themselves.

\subsubsection{Theoretical Framework}

Hüttemann (1997) offers a categorization scheme for the different types of idealization that provides a suitable structure to bring transparency to the process of idealization (see also Fig. 1). His suggestions are summarized in Table 1. The categories are not ranked. However, from the point of view of this study, the first four categories focus on the experimental preparation of phenomena and the theoretical analysis of data. In Karl Popper's (1983) sense, such preparations are boundary conditions that are needed for further investigations. Types five to eight are closer to the idealized model itself.

Sometimes the idealizations do not fit definitively into only one of these categories. That is not due to the categorization but to the idealization itself. For example, considering the idealization of a point mass, a planet can be interpreted as a point mass in order to achieve mathematical manageability (7th idealization category) when one describes its gravitational force and therefore ignores the distribution of mass. Additionally, the point mass can be used as the basis for finding a functional dependency between actually extended bodies, as one does to describe the gravitational force between two planets (8th idealization category).

The fact that idealizations cannot always be clearly assigned is not unfortunate. In the context of science teaching, the categories - one could also say teaching actionsare intended to initiate a process of reflection, that is, an intensive intellectual discourse (Dewey, 1933).

\section{An Illustration from Geometrical Optics}

This chapter aims to illustrate the idealization process using two examples from the field of optics. After defining the experimental observation and specifying the purpose of what should be explained by a model, the categories of idealizations mentioned above are used to construct the model (understanding as an epistemic artifact, see Fig. 1). Taking into account the result of the construction process, the manipulation of the model (as a representation) can begin.

\subsection{Idealizations of Thin and Thick Lenses}

One standard idealization in optics is the thin lens (sometimes even called the ideal lens), which is used to investigate the path of light through it. The thin lens itself is an idealization. However, taking a closer look at this idealization, one recognizes even more underlying idealizations (Winkelmann, 2019). Furthermore, there are interesting phenomena to be observed on thick lenses. Using idealizations, one can construct models as representations to explain such phenomena. In the past, when electricity was not available, craftsmen used a setting to concentrate the light of a candle on the object they wanted to work on. The historical example is the spread of candlelight through a sphere of glass filled with water. Such spheres are still called cobbler's balls today. In Fig. 2, this context is recreated. After a while, small bubbles of air arise at the inner surface of the round-bottomed flask. 
Fig. 2 Setting of a cobbler's ball. Candlelight shines through the round-bottomed flask, which focuses the light
Fig. 3 The area through which the light passes is illuminated. At the edge of the area, there is a brighter ring of light
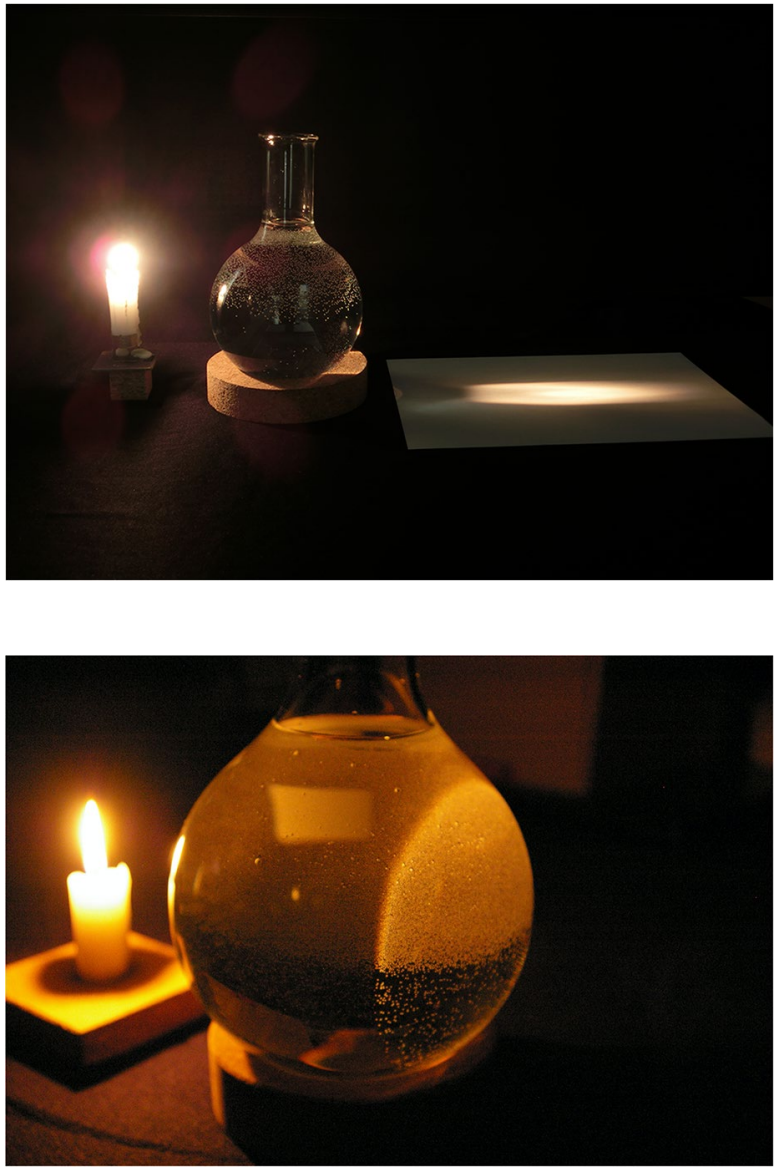

Due to this phenomenon, the area where the light has left the sphere is clearly visible. If no bubbles appear, dust can be placed on the outer surface of the flask to obtain the test arrangement.

On closer inspection, a brighter ring of light is noticeable along the edge of the area through which the light passes (Fig. 3). The ring becomes even more apparent if you look at the projection on a screen (Fig. 4a). Also, the ring is visible when monochromatic light passes through the cobbler's ball (Fig. 4b). It is an example of spherical aberration. To understand this phenomenon, a model as a representation will be constructed in the following. For this purpose, considerations on the underlying idealizations are shown first.

\subsection{Decision About Purpose}

The purpose of using a model in this situation is to understand the origin of the ring of light. Why is it brighter at the edge of the exit area? One possible way is to investigate the path of the light through the sphere of glass and water using the rules of the idealized geometrical optics model. Thinking about the purpose of the model is a crucial step in the modeling of models (Gilbert \& Justi, 2016). 
Fig. 4 a The projection of the emerging light increases the visibility of the ring. b The bright ring of light is also with monochromatic light observable
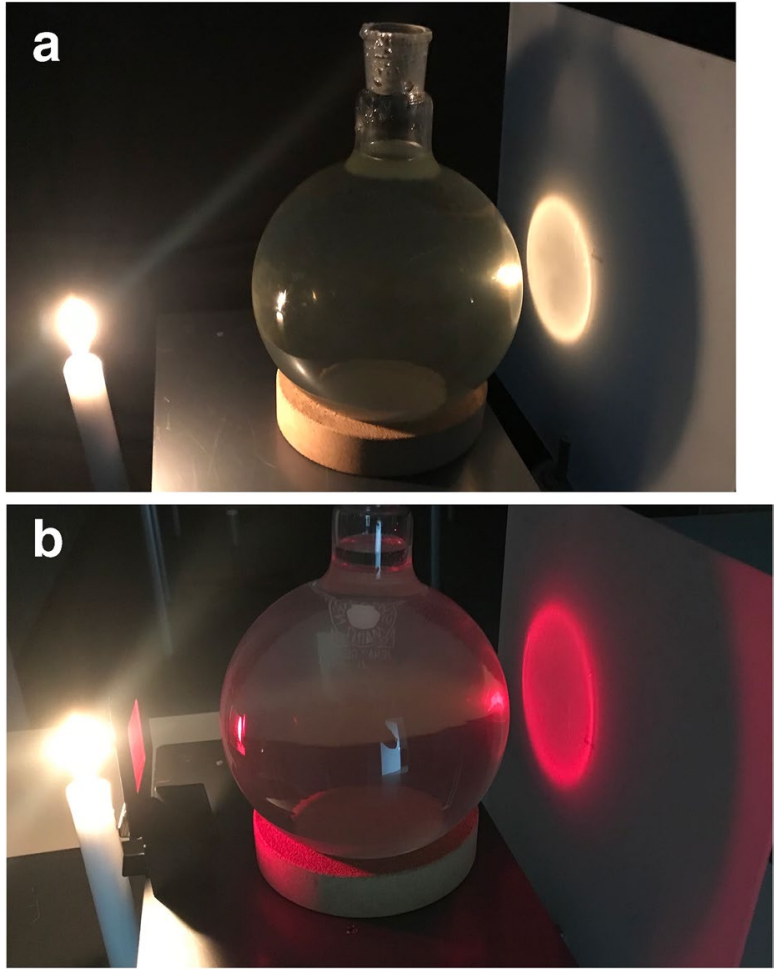

\subsection{Model as Epistemic Artifacts}

The following classification of idealizations is a suggestion and may be debatable; nonetheless, idealizations can be classified into separate categories. This requires reflection about the construction of any model and the idealizations underlying it. Some of the idealizations can be placed in several categories. However, more important than achieving the correct classification is the possibility of identifying idealizations based on the categorization system and thinking about the purpose of specific idealization by arguing its assignment.

The following list presents the idealizations that are necessary to construct a model that explains the ring of light.

\subsubsection{Preparation}

To make the ring of light visible, bubbles or dust on the surface of the sphere are needed since one cannot see the light per se, but only the things that are illuminated. 


\subsubsection{Isolation}

The darker the experimental room, the more visible the ring of light is. Through the round-bottomed flask, only the light of the candle shines at best. A dark base also reduces disturbances from other light sources.

\subsubsection{The Abstraction of Properties}

(a) For light refraction, two media with different optical densities are required. In this situation, the air is outside, and water, with a higher optical density, is inside. The properties of these two media other than their refractive index, e.g., their aggregate state, are irrelevant.

(b) The light itself can be modeled in several ways. In this approach, the property of the rectilinear propagation of light is used. Other models of light, e.g., light as waves, are not applied (initially).

\subsubsection{Idealization, More Specifically}

(a) The assumption of the ideal sphere: The sphere that is used in the described experimental setting is obviously not a perfect sphere. At the top of the sphere, there is even an extension for filling the sphere with water. Idealization makes it easier to use the mathematical description of Snellius' law to create a model with specific underlying angles as a representation.

(b) Graphical manageability: In the later model, as a representation, individual rays of light are represented by drawn lines.

\subsubsection{Simplification}

(a) Neglecting the glass; in this situation, only the refractive indices of two different media, namely, air and water, are of interest. Of course, there is refraction between the air and the glass (as well as between the glass and the water), but as a first step, it may be helpful to have a less-detailed view.

(b) Single rays of light offer clarity; understanding the relationship between light propagation outside and inside the round-bottomed flask with regard to one ray of light is more convenient than examining every possible beam of light.

(c) The origin of every beam of light is idealized to one point. In reality, the candlelight is an extended light source.

\subsubsection{The Abstraction of a Physical System}

(a) Light scattering by the bubbles or dust is essential to see the area that the light passes through as well as the ring of light. However, the question arises as to why the ring shines more brightly than the rest of the area. Since light scattering cannot explain why more light appears at the edge of the area, one can abstract from this physical system and focus on the path of the light through the sphere. 


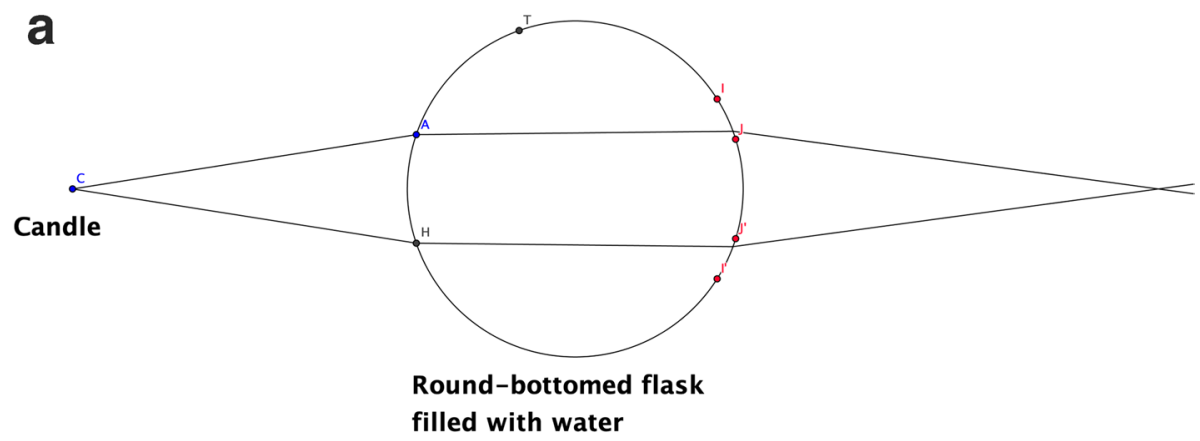

b

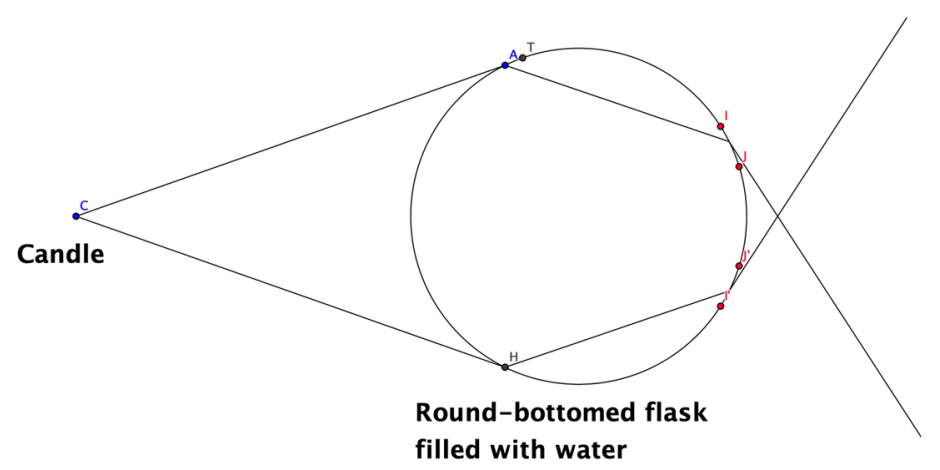

Fig. 5 a A small bundle of idealized candlelight travels through an idealized sphere and leaves the sphere between two points, I and J. b A large bundle of idealized candlelight travels through an idealized sphere and, as in the case of the small bundle, leaves it between the same two points, I and J

(b) The candle is a flickering light source. The focus of the model to be constructed lies on optics and not on thermodynamics or gas dynamics.

(c) Ignoring the colors in the ring of light: in reality, the observation of colors is possible in the experiment. These colors are due to the phenomenon of dispersion. They result in the chromatic aberration. However, this does not contribute to the explanation of the light ring. The ring can also be observed with monochromatic light (Fig. 4b).

(d) To obtain a clear representation, concentrating on a few single rays of light is helpful. Of particular interest are those rays of light that form a light bundle. All the beams within the bundle behave similarly: they are refracted. Concentrating on a few single rays of light is an abstraction of the candlelight, which radiates in all directions.

(e) To investigate the origin of the ring of light, it may be advisable to abstract several bundles of light (and their limiting light rays). How does light within a large or small light bundle travel through the cobbler's ball?

\subsection{Model as Representation}

After reflecting on the idealizations necessary for the construction of a model, the model, as a representation, can lead to further investigations. A dynamic modeling program can be used, e.g., the open-source program GeoGebra, to draw and manipulate the situation to be investigated. Figure 5a, b shows a bundle of light. The limiting rays of light in the small 
bundle (Fig. 5a) emerge from the cobbler's ball between the two red points, I and J. The limiting rays of light in the large bundle (Fig. 5b) also exit the cobbler's ball between these red points (https://www.geogebra.org/classic/csthz84b).

Now, it becomes clear that the refraction of two different light bundles leads to light amplification at the edge of the light-abandoning area. The light that refracts paraxially and the light from the farthest possible incident point meet each other at the same small band when leaving the cobblers' ball-a phenomenon caused by spherical aberration (Winkelmann, 2013). In the two-dimensional model, the overlapping of the straight light paths initially only leads to brighter light at one line (between the red points I and $\mathrm{J}$ in Fig. 5a, b). However, since the light from the candle spreads in three-dimensional space, it is not just a single ray of light that hits the cobbler's ball, but we are looking at a cone of light. The coat of this cone of light is limited by light rays spreading straight. The opening of the cone is a circle. Light bundles of different widths, or conic sections of various sizes, are considered in the model. Every single beam of these bundles continues to spread in a straight line in the cobbler's ball and finally_after twice refraction-becomes visible as a ring when leaving the cobbler's ball. The additional light in the ring must be missing elsewhere. Indeed, the shadow area outside the ring becomes larger as the lens thickness increases (in comparison to an ideal lens).

The model, as an idealized construction, builds a bridge between theory and experimentation (Fig. 1). In this case, the experiment was the starting point for further investigations. With some reflections on theoretical knowledge about optics during the construction process, it succeeded in explaining the observed phenomenon. A procedure in reverse order is also conceivable. One could manipulate the model, e.g., by varying the distance between the candle and the cobbler's ball and checking the expected observation with the experiment. In the middle of the area where the light exits the ball, another spot of light would appear. However, this further experimentation is outside the scope of this paper.

\section{Conclusions and Suggested Areas of Research}

One major goal of physics education is to give students a better understanding of physical contexts. This goal means having a good knowledge of physics and having an idea about how a scientist generates scientific findings (NOS; of course, this also applies to the other scientific disciplines). Science lessons should focus not only on imparting views of the NOS but also on promoting the ability to reflect on epistemological processes individually. Reflecting on the meaning of underlying idealizations in models (and experiments) can contribute to the development of this ability. Very few scientists-and the number is likely to approach zero for teachers-will develop a physical model on their own. Accordingly, this paper is not about constructing new scientific models in general but about building or reflecting "models as representations" in the science education discussion.

Thinking about idealizations in modern sciences is nothing new. However, reflection on idealization seems to be underrepresented in science education and science education research. Upmeier zu Belzen et al. (2019) offer a framework for modeling competence that includes the aspect nature of models, with three competence levels. To reach the second level, models are to be understood as idealized representations of something. However, examining these levels of competence is only appropriate if instruction about constructing models as representations-with the help of idealizations- has been provided. 
For this purpose, a framework with categories of idealizations has been presented in the paper and illustrated with an example. Below are three advantages of the framework of idealizations.

1. In dealing with idealizations, the aspect "nature of models" of the framework for modeling competence (Upmeier zu Belzen et al., 2019) can be trained: Identification of idealizations is made transparent through the different categories in the presented framework. More important than determining the correct classification is the possibility of identifying idealizations based on the framework and thinking about the purpose of a specific idealization by arguing for its assignment. The categories of idealizations can also be understood as objectives for action.

2. This leads to another aspect, which has not been the focus of modeling competence so far: constructing models as representations. For the construction, one has to decide which elements of the natural phenomenon in the representation are necessary to achieve the purpose of the model. A decision is therefore made about idealizations that are to apply in the model. In particular, the following categories of the framework of idealizations are helpful:

(a) Separate the entire phenomenon into concepts of the respective natural science. Given the chosen purpose of the model, not every identifiable concept has to be considered more closely ("abstraction of a physical/chemical/biological system")

(b) Emphasize or ignore particular properties ("abstraction of properties")

(c) Make mathematical simplifications ("idealization, more specifically") and

(d) Represent functional relationships that become clear this way ("simplifications and neglections")

3. Based on the cyclic process of learning about science (e.g., Teichrew \& Erb, 2020), the framework of idealizations helps to reflect models. Thinking about existing representations and thus evaluating the limits and advantages of the model is made possible by knowing the idealizations that have been carried out.

\subsection{Dealing Explicitly with Idealizations}

As mentioned above, it is common sense in science education to differentiate between several learning goals, such as learning science and learning about science.

In Hodson's (2014) sense, an explicit approach to working with models helps students assemble their knowledge.

Bearing in mind the constant need to make learning about science explicit, it is important to draw students' attention to key ideas about science, scientists and scientific practice whenever and wherever the opportunity arises (p. 2542).

This paper follows Louca and Zacharia's (2012) recommendation that model-based learning be incorporated into school science curricula in an epistemologically meaningful way. Idealizing contributes to modeling-based teaching. The explicit treatment of idealizations could be one way to develop students' understanding better and therefore place more importance on the modeling process. For teaching the NOS in general, this has been a common requirement for years. An example of the practical use of idealization is to be presented briefly from a current project. As part of a teacher training course, physics teachers 
learn to create augmented reality experiments on their own (Freese et al., 2021). First, dynamic digital models are constructed using the open-source geometry software GeoGebra (www.geogebra.org). For this to succeed, careful thinking about the relevant properties of the model - the underlying idealizations-is necessary. After that, real experiments can be viewed through a smartphone or tablet camera, and the digital models can be displayed simultaneously, thus augmenting the experiment.

Models are idealized constructions and can be interpreted as epistemic artifacts or as representations. Similar to that of Knuuttila and Voutilainen (2003), this paper notes the difference (Fig. 1). Beyond this differentiation, however, it must be highlighted that both perspectives on models are connected in the underlying idealizations. As shown in the example in Section 3, idealizations as epistemic artifacts lead to more clarity in the representation; at the same time, the abstraction of the "model as representation" from reality is reinforced by the idealizations. In Fig. 5a,b an expert sees small or large bundles of light in the model; an inexperienced learner only recognizes lines and geometric shapes. Those idealizations define the characteristics of the model. This epistemic, cognitive process of (re)constructing a model by idealizations is challenging and may be too difficult for students on their own (Leisner, 2005), if it is not discussed explicitly.

Models in science always have a certain provisional nature and therefore entail some uncertainty, which is perceived by the students in the explanations given. Höttecke and Allchin (2020) even broaden our view of uncertainties in social life that driven by doubts about scientific knowledge spread through fake news. For a general understanding of how science works, Potochnik (2017) provides a valuable consideration that "science does not pursue truth directly but instead aims to support human cognitive and practical ends. Those are projects to which idealizations can directly contribute in a number of ways" (p. 5). An improved understanding of the NOS can reduce potential skepticism on the part of learners. With the framework of idealizations presented in this paper, it seems possible to make the existence of idealizations and their meaning explicit in class.

\subsection{More Research on the Construction of and Reflection on Models Is Required}

The importance of scientific idealizations for understanding the natural sciences has not been deliberately discussed in science education research so far. Louca and Zacharia (2012) call for further studies on the modeling process, as the focus has often been on the models as products or representations. Additionally, the literature review by Gilbert and Justi (2016, p. 64) shows that only a few studies exist about modeling-based teaching through the construction of models. Taking up their distinction between models as representations and models as epistemic artifacts, this paper proposes to expand the research focus toward a perspective of models as epistemic artifacts with the help of idealizations. The framework of model competence (Upmeier zu Belzen et al., 2019) currently offers a useful orientation for measuring model competence. In this context, Mathesius and Krell (2019) emphasize the need for additional questionnaire scales. This paper supports this suggestion and underlines the need to consider model building when assessing model competence. Following that path, Shemwell and Capps (2019) report an empirical study of synthesis modeling. The authors focus on abstractions to reveal the underlying structures of a model. However, to expand that focus, this paper defines further epistemological aspects characterized by idealizations. Idealizations form the basis for model and experimental considerations. Within the framework of idealizations suggested in this paper, abstraction is classified as one part of the process of model construction. 
To make statements about the effectiveness of the explicit consideration of idealizations for modeling competence, further empirical science education research is necessary. The following three levels seem worthwhile:

First, the actual state of addressing idealizations in the classroom should be ascertained. A teacher survey is currently being conducted to identify the role of idealizations in science teaching. The survey is intended to analyze teachers' epistemological beliefs of the importance of idealizations in science and in the context of the promotion of model competence.

Second, it is assumed that only the teaching teacher can initiate a reflection on idealizations. Depending on the actual situation to be discovered, teachers should be sensitized to this topic during their studies or through further training. Training courses to convey the presented framework also appear to be a sensible approach. In addition to geometrical optics, this approach seems worthwhile for elaborating idealizations regarding further physics topics such as atomic physics or electricity; these have already been the subjects of previous (German) research on modeling in science education (e.g., Burde \& Wilhelm, 2018; Mikelskis-Seifert \& Fischler, 2003; Mikelskis-Seifert \& Kasper, 2011).

Third, in the long term, intervention studies should examine the effect of reflecting on idealizations on pupils' and students' understanding. Such research would provide opportunities for students to develop self-awareness of their thinking processes when using models and provide strategies for teachers to develop learning outcomes related to the NOS.

Availability of Data and Material Not applicable

Code Availability Not applicable

Author Contribution Not applicable

Funding Open Access funding enabled and organized by Projekt DEAL. This work was supported by the University of Education Schwäbisch Gmünd. The author received financial support for proofreading the manuscript.

\section{Declarations}

Conflict of Interest The author declares no conflict of interest.

Open Access This article is licensed under a Creative Commons Attribution 4.0 International License, which permits use, sharing, adaptation, distribution and reproduction in any medium or format, as long as you give appropriate credit to the original author(s) and the source, provide a link to the Creative Commons licence, and indicate if changes were made. The images or other third party material in this article are included in the article's Creative Commons licence, unless indicated otherwise in a credit line to the material. If material is not included in the article's Creative Commons licence and your intended use is not permitted by statutory regulation or exceeds the permitted use, you will need to obtain permission directly from the copyright holder. To view a copy of this licence, visit http://creativecommons.org/licenses/by/4.0/.

\section{References}

Akerson, V. L., Hanson, D. L., \& Cullen, T. A. (2007). The influence of guided inquiry and explicit instruction on K-6 teachers' views of nature of science. Journal of Science Teacher Education, 18(5), 751772. https://doi.org/10.1007/s10972-007-9065-4

Allchin, D. (2013). Teaching the nature of science: Perspectives \& resources. Ships Education Press. 
Burde, J.-P., \& Wilhelm, T. (2018). Concept and empirical evaluation of a new curriculum to teach electricity with a focus on voltage. In L. Ding, A. Traxler, \& Y. Cao (Eds.). 2017 Physics Education Research Conference Proceedings (pp. 68-71). https://doi.org/10.1119/perc.2017.pr.012

Chalmers, A. F. (1999). What is this thing called science? University of Queensland Press.

Coll, R. K., France, B., \& Taylor, I. (2005). The role of models/and analogies in science education: Implications from research. International Journal of Science Education, 27(2), 183-198. https://doi.org/10. 1080/0950069042000276712

Dewey, J. (1933). How we think: A restatement of the relation of reflective thinking to the educative process. Heath.

Elgin, C. (2008). Exemplification, idealization, and scientific understanding. In M. Suarez (Ed.), Fictions in Science. Philosophical Essays on Modeling and Idealization (pp. 77-90). Routledge. https://doi.org/ $10.4324 / 9780203890103$

Etkina, E., Warren, A., \& Gentile, M. (2006). The role of models in physics instruction. The Physics Teacher, 44(1), 34-39.

Freese, M., Winkelmann, J., Ullrich, M., Teichrew, A., \& Erb R. (2021). Einsatz von Augmented Reality phasenvernetzt und praxisorientiert vermittelt. In M. Kubsch, S. Sorge, J. Arnold \& N. Graulich (Hrsg.), Praxishandbuch für die Lehre in den Didaktiken der Naturwissenschaften (S. 237-242 ). Münster: Waxmann.

Gilbert, J. K., \& Boutler, C. (1998). Learning science through models and modeling. In B. Fraser \& K. Tobin (Eds.), International handbook of science education (pp. 53-66). Kluwer Academic Publishers.

Gilbert, J. K., \& Justi, R. (2016). Modelling-based teaching in science education (models and modeling in science education, vol. 9). Springer International Publishing.

Gobert, J. D., O’Dwyer, L., Horwitz, P., Buckley, B., Levy, S., \& Wilensky, U. (2011). Examining the relationship between students' understanding of the nature of models and conceptual learning in Biology, Physics, and Chemistry. International Journal of Science Education, 33(5), 653-684. https://doi.org/ $10.1080 / 09500691003720671$

Gouvea, J., \& Passmore, C. (2017). Models of' versus 'models for. Science \& Education, 26(1-2), 49-63. https://doi.org/10.1007/s11191-017-9884-4

Gut, C., Pfirter, H., \& Tardent, J. (2016). Natur und Technik. Modellkompetenz im Naturwissenschaftsunterricht - Förderung und DiagNOSe. In M. Naas (Ed.), Kompetenzorientierter Unterricht auf der Sekundarstufe I. Erziehungswissenschaftliche und fachdidaktische Perspektiven (pp. 227-249). Bern: hep.

Haase, M. (1996). Pragmatic idealization and structuralist reconstructions of theories. Journal for General Philosophy of Science, 27(2), 215-234. https://doi.org/10.1007/BF02262614

Halloun, I. A. (2004). Modeling theory in science education. Kluwer Academic.

Hertz, H. (1894). Die Prinzipien der Mechanik in neuem Zusammenhange dargestellt.

Hodson, D. (1993). Re-thinking old ways: towards a more critical approach to practical work in school science. Studies in Science Education, 22, 85-142. https://doi.org/10.1080/03057269308560022

Hodson, D. (2014). Learning science, learning about science, doing science: Different goals demand different learning methods. International Journal of Science Education, 36(15), 2534-2553. https://doi.org/ 10.1080/09500693.2014.899722

Höttecke, D., \& Allchin, D. (2020). Reconceptualizing nature-of-science education in the age of social media. Science Education, 104(4), 641-666. https://doi.org/10.1002/sce.21575

Hüttemann, A. (1997). Idealisierungen und das Ziel der Physik. In Eine Untersuchung zum Realismus, Empirismus und Konstruktivismus in der Wissenschaftstheorie. De Gruyter.

Kipnis, N. (1998). Theories as models in physics teaching. Science \& Education, 7, 245-260.

Khishfe, R., \& Abd-El-Khalick, F. (2002). Influence of explicit and reflective versus implicit inquiry-oriented instruction on sixth graders' views of nature of science. Journal of Research in Science Teaching, 39, 551-578. https://doi.org/10.1002/tea.10036

KMK; Sekretariat der Ständigen Konferenz der Kultusminister der Länder in der Bundesrepublik Deutschland (2005). Bildungsstandards im Fach Physik für den Mittleren Schulabschluss: Beschluss vom 16.12.2004. Luchterhand. Retrieved March 10, 2021, from https://www.kmk.org/fileadmin/veroe ffentlichungen_beschluesse/2004/2004_12_16-Bildungsstandards-Physik-Mittleren-SA.pdf

Knuuttila, T., \& Voutilainen, A. (2003). A parser as an epistemic artifact: A material view on models. Philosophy of Science, 70(5), 1484-1495. https://doi.org/10.1086/377424

Krell, M., Upmeier zu Belzen, A., \& Krüger, D. (2016). Modellkompetenz im Biologieunterricht. In A. Sandmann \& P. Schmiemann (Eds.), Biologiedidaktische Forschung: Band 1. Schwerpunkte und Forschungsstände (pp. 83-102). Logos. 
Lederman, N. G., Abd-El-Khalick, F., Bell, R. L., \& Schwartz, R. S. (2002). Views of nature of science questionnaire: Toward valid and meaningful assessment of learners' conceptions of nature of science. Journal of Research in Science Teaching, 39(6), 497-521. https://doi.org/10.1002/tea.10034

Lederman, N. G., Antink, A., \& Bartos, S. (2014). Nature of science, scientific inquiry, and socio- scientific issues arising from genetics: A pathway to developing a scientifically literate citizenry. Science \& Education, 23(2), 285-302. https://doi.org/10.1007/s11191-012-9503-3

Lederman, N. G. (2007). Nature of science: past, present, future. In S. Abell \& N. Lederman (Eds.), Handbook of research on science education (pp. 831-879). Lawrence Erlbaum.

Lehrer, R., \& Schauble, L. (2006). Scientific thinking and science literacy: Supporting development in learning in contexts. In W. Damon, R. M. Lerner, K. A. Renninger, \& I. E. Sigel (Eds.), Handbook of child psychology (Vol. 4, 6th ed.). Wiley.

Leisner, A. (2005). Entwicklung von Modellkompetenz im Physikunterricht. Eine Evaluationsstudie in der Sekundarstufe I. In H. Niedderer, H. Fischler, \& E. Sumfleth (Eds.), Studien zum Physik- und Chemielernen (Vol. 44). Logos.

Losee, J. (2001). A historical introduction to the philosophy of science (4th ed.). Oxford University Press.

Louca, L. T., \& Zacharia, Z. C. (2012). Modeling-based learning in science education: Cognitive, metacognitive, social, material and epistemological contributions. Educational Review, 64(4), 471-492. https:// doi.org/10.1080/00131911.2011.628748

Mathesius, S., \& Krell, M. (2019). Assessing modeling competence with questionnaires. In A. U. z. Belzen, D. Krüger, \& J. van Driel (Eds.), Towards a competence-based view on models and modeling in science education. (Models and Modeling in Science Education, vol. 12) (pp. 117-129). Springer.

Matthews, M. R. (1987). Experiment as the objectification of theory: Galileo's revolution. In Proceedings of the Second International Seminar on Misconceptions and Educational Strategies in Science and Mathematics, 1 (pp. 289-298). Cornell University.

Matthews, M. R. (2004). Idealisation and Galileo's pendulum discoveries: Historical, philosophical and pedagogical considerations. Science \& Education, 13(7), 689-715. https://doi.org/10.1007/ s11191-004-9513-X

Mikelskis-Seifert, S., \& Fischler, H. (2003). Die Bedeutung des Denkens in Modellen bei der Entwicklung von Teilchenvorstellungen - Empirische Untersuchung zur Wirksamkeit der Unterrichtskonzeption. Zeitschrift für Didaktik der Naturwissenschaften, 9, 89-103.

Mikelskis-Seifert, S., \& Kasper, L. (2011). Modellieren in der Physik, im Alltag und im Unterricht. Naturwissenschaften im Unterricht Physik, 122(22), 4-12.

Morrison, M., \& Morgan, M. (1999). Models as mediating instruments. In M. Morgan \& M. Morrison (Eds.), Models as mediators (pp. 10-37). Cambridge University Press.

National Research Council. (2007). Taking Science to School: Learning and Teaching Science in Grades $K-8$. Committee on Science Learning, Kindergarten Through Eighth Grade. Richard A. Duschl, Heidi A. Schweingruber, and Andrew W. Shouse, Editors. Board on Science Education, Center for Education. Division of Behavioral and Social Sciences and Education. Washington, DC: The National Academies Press.

NGSS Lead States (2013). Next generation science standards: For states, by states. Appendix H. Retrieved March 10, 2021, from http://www.nextgenscience.org/next-generation-science-standards

Niaz, M. (1999). The role of idealization in science and its implications for science education. Journal of Science Education and Technology, 8(2), 145-150. https://doi.org/10.1023/A:1018661017176

Nola, R. (2004). Pendula, models, constructivism and reality. Science \& Education, 13(7), 346-377. https://doi.org/10.1023/B:SCED.0000041832.90947.b1

Nowak, I., \& Nowak L. (1998). "Model(s)" and "experiment(s) as homogeneous families of notions. In Niall Shanks (Ed.), Idealization IX: Idealization in contemporary physics (pp. 35-50). Rodopi B. V.: Amsterdam.

Oh, P. S., \& Oh, S. J. (2011). What teachers of science need to know about models: An overview. International Journal of Science Education, 33(8), 1109-1130. https://doi.org/10.1080/09500693.2010. 502191

Pluta, W. J., Chinn, C. A., \& Duancan, R. G. (2011). Learners' epistemic criteria for good scientific models. Journal of Research in Science Teaching, 48(5), 486-511. https://doi.org/10.1002/tea. 20415

Popper, K. (1983). Realism and the aim of science. Hutchinson.

Portides, D. P. (2007). The relation between idealisation and approximation in scientific model construction. Science \& Education, 16(7), 699-724. https://doi.org/10.1007/s11191-006-9001-6

Potochnik, A. (2017). Idealization and the aims of science. University of Chicago Press.

Rheinberger, H.-J. (2007). Historische Epistemologie zur Einführung (2. Auflage ed.). Junius. 
Romer, R. H. (1993). Reading the equations and confronting the phenomena. The delights and dilemmas of physics teaching. American Journal of Physics, 61(2), 128-142. https://doi.org/10.1119/1.17327

Rönnebeck, S., Bernholt, S., \& Ropohl, M. (2016). Searching for a common ground: A literature review of empirical research on scientific inquiry activities. Studies in Science Education, 52(2), 161-197. https://doi.org/10.1080/03057267.2016.1206351

Schön, D. A. (1983). The reflective practitioner: How professionals think in action. Basic Books.

Schwartz, R. S., Lederman, N. G., \& Crawford, B. A. (2004). Developing views of nature of science in an authentic context: An explicit approach to bridging the gap between nature of science and scientific inquiry. Science Education, 88(4), 610-645. https://doi.org/10.1002/sce.10128

Schwarz, C. V., \& White, B. Y. (2005). Metamodeling knowledge: Developing students' understanding of scientific modeling. Cognition and Instruction, 23(2), 165-205. https://doi.org/10.1207/s1532 690xci2302_1

Schwarz, C. V., Reiser, B. J., Davis, E. A., Kenyon, L., Acher, A., Fortus, D., Shwartz, Y., Hue, B., \& Krajcik, J. (2009). Developing a learning progression for scientific modeling: Making scientific modeling accessible and meaningful for learners. Journal of Research in Science Teaching, 46(6), 632-654. https://doi.org/10.1002/tea.20311

Shemwell, J. T., \& Capps, D. K. (2019). Learning abstraction as a modeling competence. In A. U. z. Belzen, D. Krüger, \& J. van Driel (Eds.), Towards a competence-based view on models and modeling in science education (Models and Modeling in Science Education, vol. 12.) (pp. 291-307). Springer.

Sins, P. H. M., Savelsbergh, E. R., van Joolingen, W. R., \& van Hout-Wolters, B. H. A. M. (2009). The relation between students' epistemological understanding of computer models and their cognitive processing on a modelling task. International Journal of Science Education, 31(9), 1205-1229. https://doi. org/10.1080/09500690802192181

Strevens, M. (2017). How idealizations provide understanding. In S. R. Grimm, C. Baumberger, \& S. Ammon (Eds.), Explaining understanding: New essays in epistemology and the philosophy of science (pp. 37-49). Routledge.

Suárez, M. (2003). Scientific representation: Against similarity and isomorphism. International Studies in the Philosophy of Science, 17(3), 225-244. https://doi.org/10.1080/0269859032000169442

Teichrew, A., \& Erb, R. (2020). Lernen mit Modellen und Experimenten: Von der Beobachtung zur Erkenntnis am Beispiel des Regenbogens. $M N U, 73(6), 481-486$.

Tempel, B., Randler, C., Rehm, M., \& Wilhelm, M. (2018). Model competences in chemistry and biology lessons - what skills do teachers need? A systematic literature review; Modellkompetenzen im Chemie- und Biologieunterricht - welche Fähigkeiten brauchen Lehrkräfte? Ein systematisches Literaturreview. Progress In Science Education (PriSE), 1(1). https://doi.org/10.25321/prise.2018.471

Treagust, D. F., Chittleborough, G., \& Mamiala, T. L. (2002). Students' understanding of the role of scientific models in learning science. International Journal of Science Education, 24(4), 357-368. https:// doi.org/10.1080/09500690110066485

Upmeier zu Belzen, A., van Driel, J., \& Krüger, D. (2019). Introducing a framework for modeling competence. In A. Upmeier zu Belzen, D. Krüger, \& J. von Driel (Eds.), Towards a competence-based view on models and modeling in science education (Models and Modeling in Science Education, vol. 12.) (pp. 3-19). Springer.

Winkelmann, J. (2013). Das Thema Abbildungsfehler im Physikunterricht: Anschaulich an der Schusterkugel in Experiment und Simulation. Mathematisch Naturwissenschaftlicher Unterricht, 66(2), 95-99.

Winkelmann, J. (2019). Idealisierungen und Modelle im Physikunterricht. In H. Grötzebauch \& V. Nordmeier (Hrsg.). PhyDid B - Didaktik der Physik, Beiträge zur DPG-Frühjahrstagung des Fachverbands Didaktik der Physik in Aachen, 2019, 227-231.

Winkelmann, J., Freese, M., \& Strömmer, T. (2021). Schwierigkeitserzeugende Merkmale im Physikunterricht. Die Perspektive von Schüler*innen. Institute of Natural Science, University of Education Schwäbisch Gmünd. Progress in Science Education.

Publisher's Note Springer Nature remains neutral with regard to jurisdictional claims in published maps and institutional affiliations. 